\title{
Cidades em tempos de pandemia: um ensaio reflexivo
}

\author{
Giovanna Augusto Merli ${ }^{1}$ | Guilherme Silva Graciano ${ }^{2}$ \\ Recibido: 27-05-2020 | en su versión final: 08-01-2021
}

Resumo

\begin{abstract}
Este artigo nasce da inquietude frente ao momento em que o mundo atravessa, no combate a uma pandemia de escala mundial, e busca discutir qual será seu significado para as cidades tais como as conhecemos hoje. Sobre as inovações e as respostas que surgirão no modo de planejar as cidades pós pandemia de Covid-19, há mais perguntas que respostas e para o momento o que é mais válido é a reflexão sobre o assunto a fim de construir questionamentos que fomentem novas pesquisas e abordagens para o tema do planejamento urbano. Para refletir sobre possíveis respostas do urbanismo na atualidade, é feita uma revisão na historiografia do urbanismo, desde seu surgimento, no final do século XIX, discorrendo sobre como foi a resposta do planejamento urbano durante as pandemias e epidemias dos séculos XIX e XX. Este tema é debatido, explicitando-se que o urbanismo surge e se desenvolve buscando criar condições em que o contágio e surgimento de novas epidemias não aconteça, abordando casos de intervenções e planos urbanos na Europa e no Brasil. Por fim, são apontados dados da OMS e da ONU que demonstram que o cenário pandêmico pode se tornar habitual e, os reflexos já observados nas cidades e sociedades, para refletir sobre uma possível resposta do planejamento urbano para o pós-COVID-19 e para o papel dos arquitetos e urbanistas frente a esta crise. É reforçada ideia de que as cidades refletem a sociedade e que esta resposta depende de mudanças que impactam economia e organização social.
\end{abstract}

Palabras chave: Pandemia; cidades; planejamento urbano; COVID-19

Citação Augusto Merli, G. \& Silva Graciano, G. (2021). Cidades em tempos de pandemia: um ensaio reflexivo. ACE: Architecture, City and Environment, 16(46), 9375. DOl: http://dx.doi.org/10.5821/ace.16.46.9375

\section{Cities in Times of Pandemic: a Reflective Essay}

Abstract

\begin{abstract}
This article is born out of the concern about the moment that the world is going through, in the fight against a world-wide pandemic, and seeks to discuss what it will mean for cities as we know them today. Regarding the innovations and responses that will arise in the way of planning post-pandemic cities of Covid-19, there are more questions than answers and for the moment what is most valid is the reflection on the subject to build questions that encourage new research and approaches to the theme of urban planning. To reflect on possible responses of urbanism today, a review is made of the historiography of urbanism, since its emergence in the late 19th century, discussing how the response of urban planning was during the pandemics and epidemics of the 19th and 20th centuries. This topic is debated, explaining that urbanism appears and develops seeking to create conditions in which the contagion and emergence of new epidemics does not happen, addressing cases of interventions and urban plans in Europe and Brazil. Finally, data from the WHO and the UN are pointed out that demonstrate that the pandemic scenario may become habitual and, the reflexes already observed in cities and societies, to reflect on a possible response of urban planning for the post Covid-19 and for the role of architects and urban planners in the face of this crisis. It reinforces the idea that cities reflect society, and that this response depends on changes that impact the economy and social organization.
\end{abstract}

Keywords: Pandemic; cities; urban planning; COVID-19

${ }^{1}$ Mestre em arquitetura e urbanismo, Universidad del Bío-Bío (ORCiD: 0000-0003-3933-9688), ${ }^{2}$ Mestre em arquitetura e urbanismo, Escola Superior de Administração, Marketing e Comunicação. Correo de contacto: gmerli4@gmail.com

ACE, 16 (4.6) CC BY-ND 3.0 ES | UPC Barcelona, España | Cidades em tempos de pandemia: um ensaio reflexivo.

DOI: http://dx.doi.org/10.5821/ace.16.46.9375 


\section{Introdução}

O trabalho aqui apresentado é resultado de um exercício de reflexão sobre a estreita relação de transformação entre pandemias e o espaço das cidades. Assumindo que a disciplina do urbanismo se origina a partir da necessidade de tornar as cidades mais salubres, em um enfrentamento direto às crises sanitárias da transição do século XIX para o século XX, entende-se que as pandemias tiveram um influente papel no desenvolvimento de práticas e teorias de urbanização e desenho urbano. Porém, essa influência se demonstrou um caminho de duas mãos, uma vez que as condições materiais das cidades contemporâneas (as aglomerações, as altas densidades populacionais, a desigualdade social e de acessos) são fatores relevantes para a disseminação de doenças em escala global atualmente. É feita uma revisão histórica sobre a associação entre o urbanismo e as crises sanitárias que originaram e influenciaram o planejamento urbano como temos hoje, para, por fim, discorrer sobre a situação atual e suas perspectivas para as cidades.

Propõe-se, baseado na histórica relação entre cidades e epidemias/pandemias, e as consequências, dados e projeções referentes a atual crise do COVID 19, refletir sobre os possíveis futuros de cidades provenientes de uma realidade de constante risco de pandemia (OMS, 2019), buscando compreender quais serão as novas relações de valor, econômico e simbólico, e as novas dinâmicas entre pessoas e espaços urbanos.

\section{O urbanismo como resposta a crises sanitárias}

As grandes revoluções no modo de pensar a cidade tiveram ligação com a proliferação de doenças, com epidemias como a peste e com a discussão de como evitar contágios através do urbanismo, com a reorganização do espaço urbano e a adoção de soluções sanitárias. É possível considerar que as epidemias sempre foram responsáveis por remodelar a cidade. Desde o surgimento do urbanismo enquanto ciência, na transição do século XIX para o século XX, a preocupação sanitária é fundamental para justificar as reformas no espaço. Epidemias causam mudanças significativas no modo de pensar e agir da sociedade. Novos hábitos são incorporados e novas rotinas são criadas. Como a cidade é um reflexo da sociedade, uma materialização da organização social, estas mudanças são refletidas na organização do espaço urbano. Isto aconteceu ao longo da história e acontece novamente na atualidade, com a pandemia de Covid-19.

De acordo com o urbanista brasileiro Flávio Villaça (1997), a cidade "é socialmente produzida e ao mesmo tempo reage sobre o social”, ou seja, ao mesmo tempo que a cidade é uma materialização da estrutura da sociedade, com seus hábitos e costumes, as intervenções no espaço urbano e a reorganização das cidades buscam reinventar a própria organização social. Na superação de epidemias, a reorganização do espaço urbano se mostrou sempre como um fator fundamental para a solução da crise. Remodelar as cidades torna-se uma tentativa, mesmo que utópica, de remodelar a própria sociedade para a superação de epidemias. As condições de superpovoamento das cidades no início da Revolução Industrial, juntamente com os problemas sanitários daquele período, levaram a epidemias que foram responsáveis pelo surgimento do urbanismo como conhecemos hoje, uma ciência com o intuito de estudar o espaço urbano para propor soluções. A cidade de Londres, pioneira na industrialização, juntamente com outras cidades industriais na Europa e América, tinham péssimas condições sanitárias na década de 1830(Figura 1 e 2). Estas cidades industriais não dispunham de abastecimento de água e captação de esgoto nem mesmo nos bairros onde estavam localizadas as elites e a burguesia. As pessoas se aglomeravam ao redor das fábricas, e o ambiente urbano era marcado por ruas imundas, com esgoto a céu aberto e acúmulo de lixo, ambiente propício para a proliferação de doenças (Gonçalves. et al., 2006).

ACE, 16 (4.6) CC BY-ND 3.0 ES | UPC Barcelona, España | Cidades em tempos de pandemia: um ensaio reflexivo.

DOI: http://dx.doi.org/10.5821/ace.16.46.9375 


\section{ACE Architecture, City and Environment}

E-ISSN 1886-4805

Enormes contingentes populacionais rurais dirigiam-se atônitos rumo às chaminés que brotavam nas velhas cidades, durante os séculos XVIII e XIX. Ao longo de décadas, as pessoas disputavam cada metro quadrado da cidade, convivendo com as mais trágicas condições de vida. Como num formigueiro, aglomeravam-se ao redor das fábricas, ao longo de ruas imundas, nas quais o esgoto, que corria a céu aberto, e montanhas de lixo dominavam a paisagem. Epidemias proliferavam sem controle, e as condições desumanas de trabalho nas fábricas não mediam horas nem respeitavam idade. (Gonçalves. et al., 2006)

Neste contexto caótico, marcado por epidemias de cólera e outras doenças, surge o urbanismo como disciplina, buscando reordenar o espaço da cidade e ajudar a criar hábitos, pelo menos para as classes mais abastadas. Até então, não havia o hábito de banhos diários e higienização das roupas. A criação de costumes mais higiênicos passava pela disponibilização de infraestrutura para isto (MACEDO, 2008).

As inovações deste período, que buscavam pôr fim às epidemias de cólera que assolavam cidades como Paris e Londres, passaram a ter como estratégia soluções ditadas por engenheiros e pelos primeiros "urbanistas", termo que só passou a ser utilizado após Cerdá cunhar o conceito de "urbanismo" (Cerdá, 1867). Os primeiros urbanistas se tornaram figuras heroicas, pois lidavam com a solução de problemas de saúde pública de forma mais contundente que os médicos, que não tinham ideias realistas de como prevenir a tuberculose ou as causas das epidemias, que eram creditadas ao que era denominado de miasmas, ou ares contaminados (Ezquiaga, 2020).

Durante o século XIX ficaram mais claras as competências de cada profissional. Com o fim da teoria dos miasmas, que não conseguiam responder sobre as origens e sobre as transmissões das doenças, e com o surgimento das vacinas, os médicos concentram sua atuação aos cuidados com os indivíduos, enquanto os urbanistas e engenheiros "passaram a desenvolver obras a partir dos princípios do urbanismo sanitarista" (Müller, 2002).

Figura 1. Ruas de Londres no final do século XIX

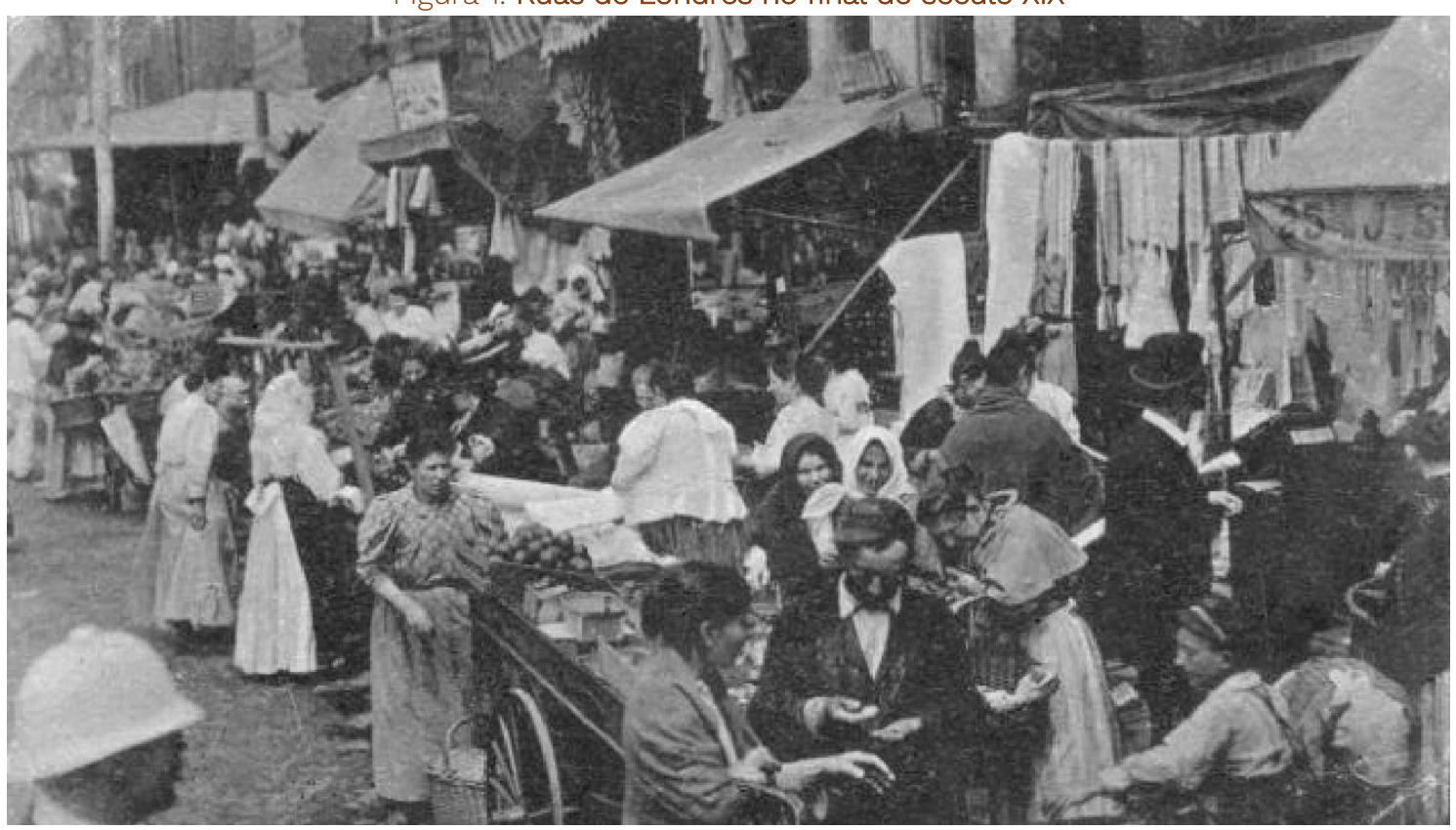

Fonte: Getty Images.

ACE, 16 (46) CC BY-ND 3.0 ES | UPC Barcelona, España | Cidades em tempos de pandemia: um ensaio reflexivo. 


\section{ACE Architecture, City and Environment}

E-ISSN 1886-480

Figura 2. Alta densidade populacional e pessoas amontoadas em habitações precárias próximo a fábricas em Londres no final do século XIX

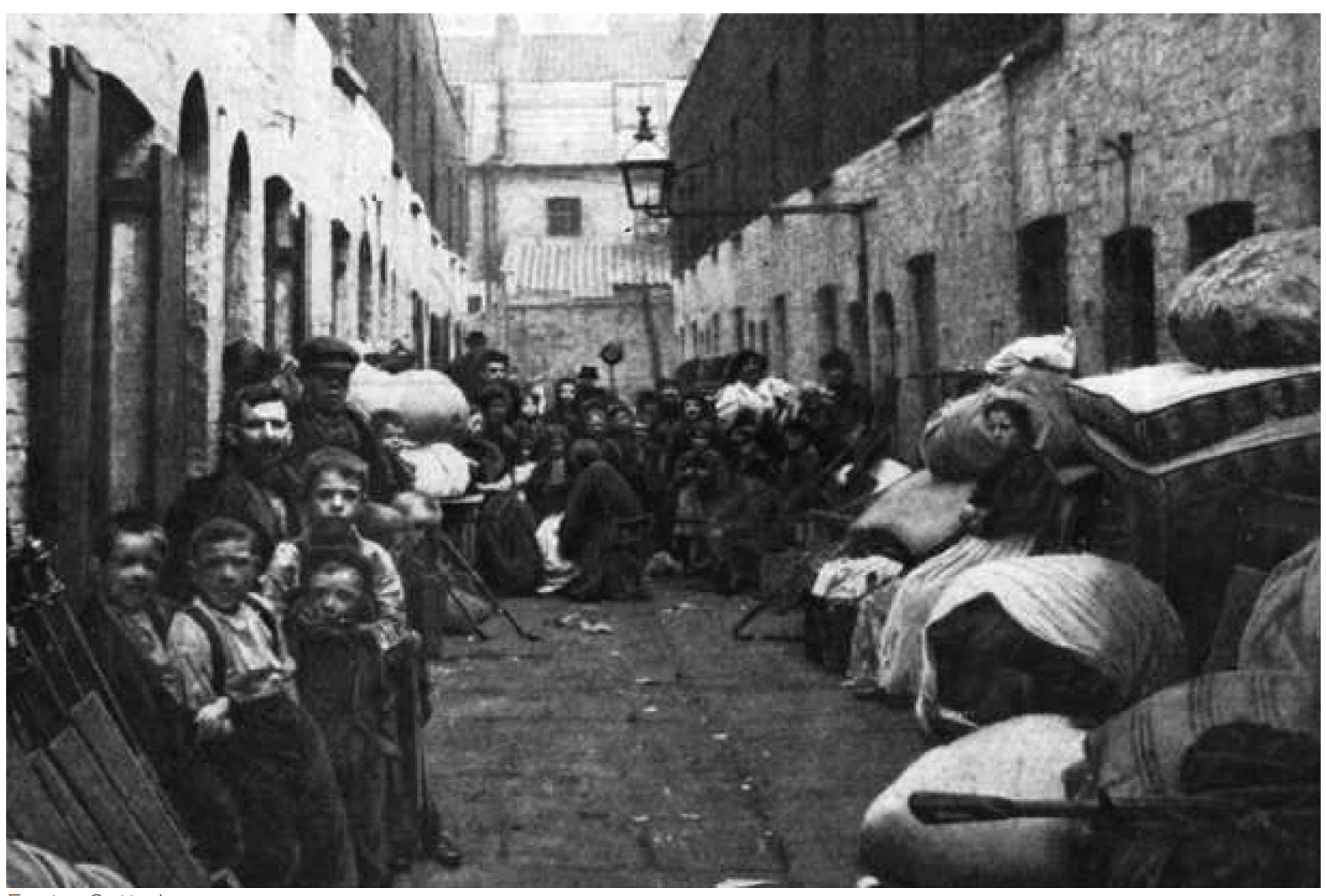

Fonte: Getty Images

As intervenções urbanas deste período são denominadas de "sanitaristas" ou "higienistas", pois buscavam criar condições para que a sociedade pudesse se organizar de maneira mais saudável, com a cidade organizada de tal forma que evitasse as condições que levavam à proliferação de doenças. O exemplo mais famoso deste período, que posteriormente virou um modelo, seguido por várias cidades ao redor do mundo, foi o plano de George Haussmann para Paris.

A intervenção que o administrador Haussmann executou em Paris, entre as décadas de 1850 e 1870 , tinha como objetivo melhorar a circulação na cidade e eliminar a insalubridade, permitindo maior acesso à luz, ventilação e maior arborização. Um de seus principais objetivos foi o de modernizar a cidade e permitir que tropas do governo se movimentassem com maior facilidade para manter a ordem pública em tempos de distúrbio. Paralelo a este objetivo militar, as amplas avenidas que foram rasgadas no antigo tecido urbano de origem medieval, juntamente com os parques, vias arborizadas e rede de esgoto, possibilitaram que Paris se livrasse de anos de epidemias de cólera e tifo. Todas essas mudanças foram possíveis a partir da demolição de grandes áreas do centro da cidade e da expulsão da população mais pobre para a periferia (Benevolo, 1993; Glancey, 2016).

O Plano Haussmann para Paris foi modelo para o Plano de Pereira Passos para o Rio de Janeiro, no início do século XX. A cidade do Rio, que era na época a capital do Brasil, possuía graves problemas sanitários. As ruas estreitas, cheias de lixo e esgoto, juntamente com habitações coletivas superlotadas, denominadas de "cortiços" (Figura 3), favoreciam o surgimento de epidemias. A administração do presidente Rodrigues Alves, entre 1902 e 1906, colocou como compromisso de governo a questão do saneamento e saúde pública. Pereira Passos, engenheiro e prefeito nomeado da então capital do Brasil, executou a reforma que demoliu boa parte do antigo casario do centro da cidade, ampliou avenidas e criou redes de esgoto e de abastecimento de água (Figura 4). Para

ACE, 16 (4.6) CC BY-ND 3.0 ES | UPC Barcelona, España | Cidades em tempos de pandemia: um ensaio reflexivo. 4

DOI: http://dx.doi.org/10.5821/ace.16.46.9375 
controlar a epidemia de varíola, nesta mesma época o sanitarista Oswaldo Cruz planejou uma campanha de vacinação compulsória, gerando a revolta popular de 1904 chamada "revolta da vacina". A população mais pobre, excluída do planejamento, que contava com os cortiços enquanto habitações coletivas que reuniam várias famílias, após a demolição do centro da cidade, migra para os morros construindo seus barracos com o material da demolição do centro do Rio de Janeiro, marcando a primeira fase de favelização da cidade (Fiocruz, 2020).

Figura 3. Cortiço do centro do Rio de Janeiro no início do século XX

Fonte: FIOCRUZ

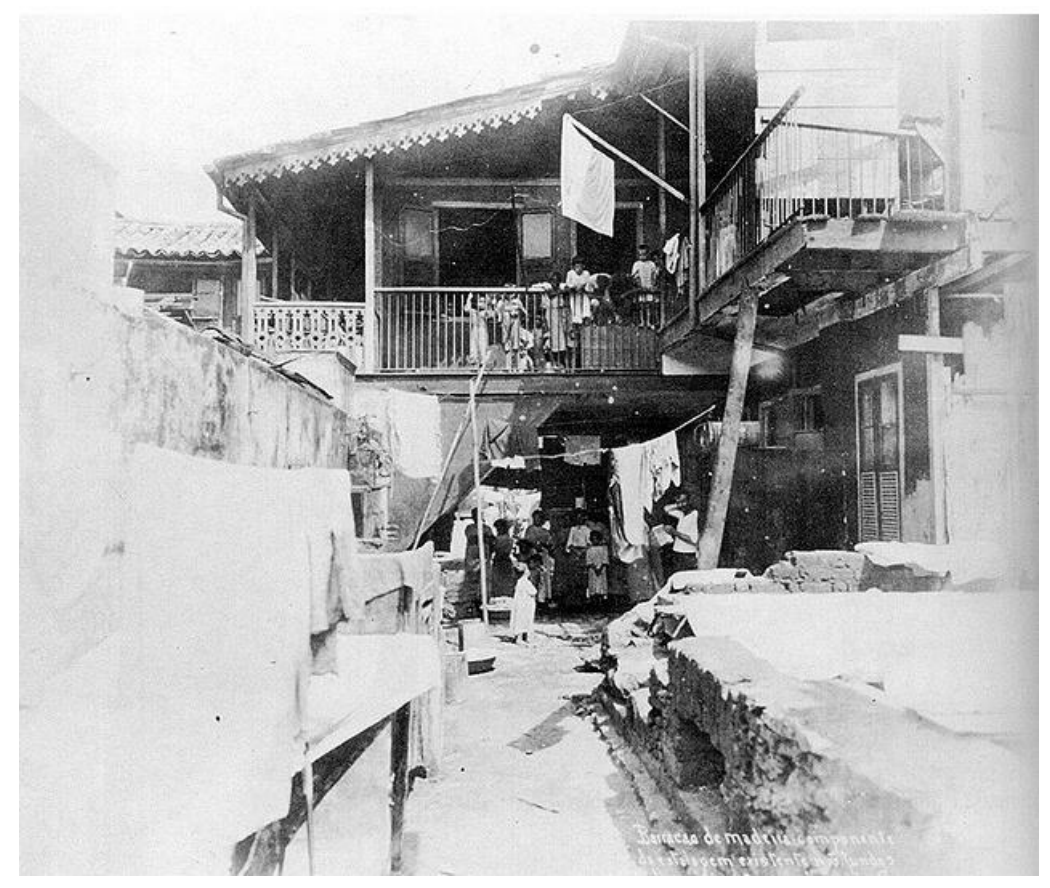

Figura 4. Demolições no centro do Rio de Janeiro durante a reforma de Pereira Passos, no início do século XX

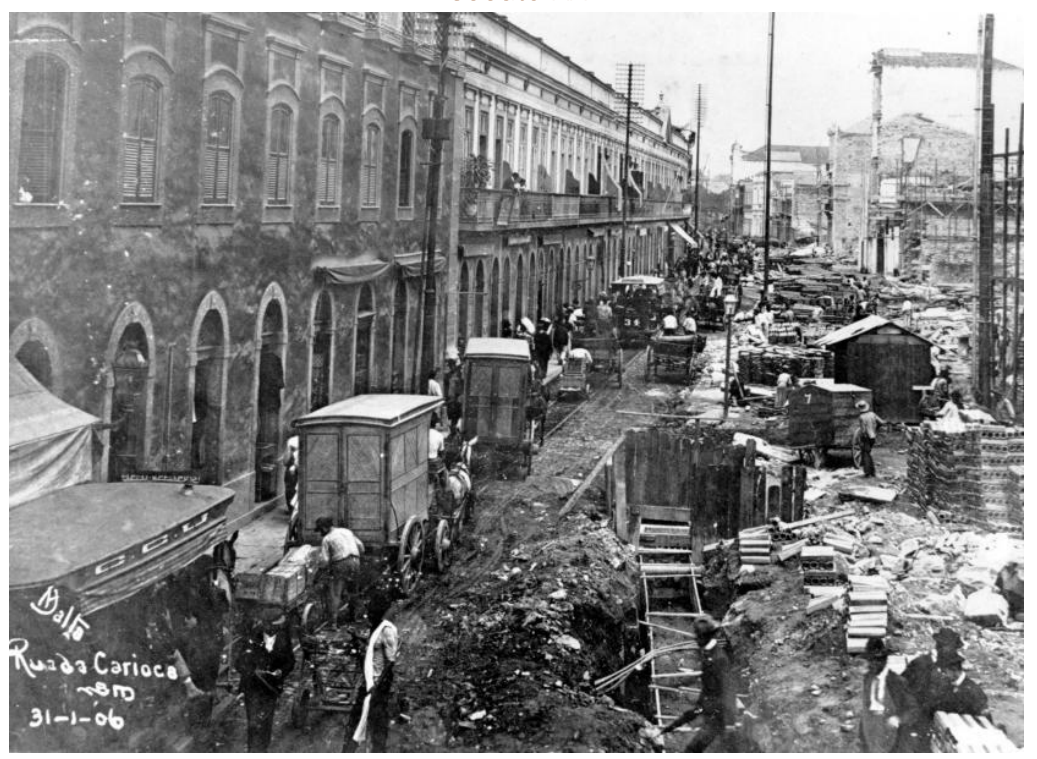

Fonte: FIOCRUZ.

ACE, 16 (46) CC BY-ND 3.0 ES | UPC Barcelona, España | Cidades em tempos de pandemia: um ensaio reflexivo. 
As condições precárias em que viviam a população mais pobre leva a um modelo de urbanismo, chamado higienista, que passa a servir também como um pretexto para um "higienismo social", apartando os mais pobres no espaço das cidades. Os pobres, na ideologia do planejamento urbano do início do século XX não são vistos como uma "classe perigosa" devido somente à possibilidade de oferecer algum problema para a ordem pública e a segurança, os pobres também apresentariam "riscos de contágio" (Chalhoub, 2006).

"A cidade demanda uma intervenção da ordem e disciplina das condições de vida e do próprio trabalho por meio da higiene pública. Utiliza-se dos discursos do progresso como uma utopia para que se possa disciplinar os espaços e corpos. Também a pobreza é associada às doenças causadas pela falta de higiene em moradias insalubres e aos odores exalados pelos ambientes propícios as propagações e manifestações perigosas de todo tipo, inclusive doenças contagiosas. Por isso, o estudo pela medicina será tão importante para compreender o corpo nos mínimos detalhes, para além da aparência. Geralmente, nesses ambientes, ocorre a degeneração do corpo físico e social. Um exemplo comum são os cortiços e as emanações de ratos, micróbios e contaminações perigosas do homem degenerado. Motivo de preocupação das elites e autoridades. Representa também uma ameaça à própria moralidade burguesa cristã da família, em especial os locais lascivos e destruidores de lares, como os prostíbulos, geralmente localizados em áreas deterioradas da região central." (Oliveira Sobrinho, 2013, p.213-214)

Para apartar este problema social e de saúde pública, a setorização torna-se um instrumento de planejamento urbano recorrente em países desiguais como o Brasil. A segregação funciona como uma política de planejamento para manter algumas partes das cidades livres de cortiços e tipos de habitação que pudessem oferecer algum risco sanitário ou à ordem pública, ou seja, garante que alguns bairros sejam ocupados pela elite e classe média e que os mais pobres vivam na periferia ou em favelas. Como fator agravante, os investimentos do poder público em infraestrutura e saneamento irão priorizar a parte da cidade voltada para as elites e classes média, enquanto a periferia continua reproduzindo e mantendo as condições sanitárias que favorecem o surgimento de epidemias (Villaça, 2012).

O ideal de limpeza e o desejo utópico do progresso irá guiar o planejamento urbano do início do século XX, que irá controlar os espaços da cidade e excluir a pobreza de áreas ditas "nobres". Esta concepção higienista estará presente também na construção de grandes avenidas e áreas arborizadas, que em países latino-americanos como o Brasil, vinha acompanhado da importação de hábitos estrangeiros e "mais civilizados" do ponto de vista das elites. Dessa forma, em São Paulo, por exemplo, há a construção de bairros como os Campos Elíseos, Bela Vista e Higienópolis (cidade da higiene), voltados para as elites econômicas produtoras de café (Oliveira Sobrinho, 2013).

A transição do final do século XIX para o início do século XX marca no Brasil o período de transição entre o período de monarquia e a república, com a mudança das relações de produção baseadas na escravidão para uma produção essencialmente capitalista. Foi neste contexto que se deu a implantação das políticas e reformas sanitaristas que passaram a vigorar em boa parte do país. Essas políticas surgem como "uma articulação das elites econômicas e intelectuais, visando interesses próprios, fruto do nascimento de uma consciência da amplitude dos problemas sanitários e da proliferação das doenças", o que favoreceu o aumento da atribuição do Estado brasileiro em questões de saneamento e saúde pública (Müller, 2002).

Porém, como aponta Müller (2002), o urbanismo sanitarista no Brasil veio antes da industrialização do país, diferente da Europa, que implantou o urbanismo sanitarista em razão dos problemas causados pela industrialização.

ACE, 16 (4.6) CC BY-ND 3.0 ES | UPC Barcelona, España | Cidades em tempos de pandemia: um ensaio reflexivo.

DOI: http://dx.doi.org/10.5821/ace.16.46.9375 
"Diferentemente da Europa, a implantação do urbanismo sanitarista no Brasil não está ligada ao caos instaurado pelo processo de industrialização, seu surgimento se dá com a consolidação do modo de produção capitalista e como forma de preparação para a industrialização das cidades. As mudanças estruturais que vinham ocorrendo no século XIX, em toda Europa, serviram de modelo para que as antigas cidades coloniais brasileiras pudessem se desfazer de suas estruturas urbanas ultrapassadas, que além de não mais comportarem a população, contribuíam para gerar problemas de insalubridade, principalmente no que diz respeito à propagação de epidemias”. (Müller, 2002)

O principal nome do período sanitarista no urbanismo brasileiro foi o engenheiro Francisco Saturnino de Brito, nascido a 14 de julho de 1864, em Campos, Estado do Rio de Janeiro, e falecido a 10 de março de 1929, em Pelotas, Rio Grande do Sul. Saturnino de Brito, que era formado em engenharia civil pela Escola Politécnica do Rio de Janeiro, atuou na elaboração de diversos planos urbanos, além da construção de ferrovias e pesquisas na área de saneamento. Nos artigos que escreveu, Saturnino buscou propagar na sociedade novos valores de higiene e o uso de novas instalações sanitárias (Müller, 2002).

Saturnino de Brito, diferente de outros de sua época, optava sempre por intervenções pequenas e pontuais, em vez de grandes reformas. Ele preocupava-se por não interferir bruscamente no meio social e procurava não desestabilizar "a ordem estabelecida ou a harmonia das famílias" (Andrade, 1992). Seu principal projeto executado é o saneamento da cidade de Santos-SP, com seus canais, tendo feito também projetos para São Paulo-SP, Florianópolis-SC e diversas outras cidades. Francisco Saturnino de Brito conseguiu fazer, com seu trabalho, que o Brasil fosse um referencial em saneamento urbano a partir de meados do século XIX. Algumas cidades brasileiras tiveram implantados seus sistemas de água e esgoto antes de outras importantes cidades do mundo, como pode-se ver nas figuras 5 e 6 (Müller, 2002).

Ao longo do século XX, o urbanismo moderno continuou com este aspecto sanitarista na questão de aproveitar as novas tecnologias construtivas que permitem a verticalização para possibilitar que grandes áreas da cidade pudessem abrigar espaços verdes e que os blocos habitacionais pudessem ter ampla exposição ao sol e à ventilação, evitando doenças e contaminações. A setorização modernista, prevista na Carta de Atenas de 1933, também iria de acordo com as questões sanitárias do início do século, lembrando que o contexto do surgimento do urbanismo moderno é os pós ॥ Guerra e pós epidemia de gripe espanhola.

Figura 5. Implantação dos primeiros serviços de esgotos

\begin{tabular}{|l|c|}
\hline \multicolumn{1}{|c|}{ CIDADE } & ESGOTOS \\
\hline Hamburgo & 1853 \\
\hline Rio de Janeiro & 1864 \\
\hline Bruxelas & 1867 \\
\hline Berlim & 1874 \\
\hline Buenos Aires & 1877 \\
\hline Roma & 1879 \\
\hline Viena & 1883 \\
\hline Nápoles & 1893 \\
\hline Paris & 1894 \\
\hline
\end{tabular}

TABELA 1 - IMPLANTAC̣ÃO DOS PRIMEIROS SERVIÇOS DE

ESGOTOS.

Fonte: BRITO, Obras completas. vol. III, p. 197.

Fonte: Müller, 2002, p.39.

ACE, 16 (46) CC BY-ND 3.0 ES | UPC Barcelona, España | Cidades em tempos de pandemia: um ensaio reflexivo.

DOI: http://dx.doi.org/10.5821/ace.16.46.9375 
Figura 6. Implantação dos primeiros serviços de água e esgotos no Brasil

\begin{tabular}{|l|c|c|}
\hline CDADE & ABASTECIMENTO DE ÁGUA & SERVIÇO DE ESGOTOS \\
\hline São Paulo & 1842 & 1883 \\
\hline Porto Alegre & 1861 & 1912 \\
\hline Rio de Janeiro & 1864 & 1864 \\
\hline Recife & 1837 & 1875 \\
\hline Santos & 1907 & 1889 \\
\hline São Vicente & 1867 & 1914 \\
\hline Aracaju & 1909 & 1914 \\
\hline Curitiba & 1907 & 1910 \\
\hline Florianópolis & 1910 & 1916 \\
\hline Bagé & 1912 & 1921 \\
\hline
\end{tabular}

Tabela 2 - IMPLANTAÇÃO DOS PRIMEIROS SERVIÇOS DE ÁGUA E ESGOTOS NO BRASIL

Fontes:

BEER, $O$ novo paradigma das politicas urbana..., p. 74 .

RAMOS, Átila. Memória do saneamento desterrense. Florianópolis: Editora da CASAN, 1986. p. 72.

Fonte: Müller, 2002, p.39.

Ao longo dos séculos XIX e XX o planejamento urbano buscou criar condições que impedissem o surgimento de doenças e evitasse a contaminação. O urbanismo, desde seu surgimento enquanto disciplina, busca dar uma resposta a esta questão. Porém, os fatores que levaram aos primeiros planos urbanos ainda existem. As cidades, devido à desigualdade socioeconômica, ainda mantêm lugares que pouco se diferem de Londres e das cidades industriais do fim do século XIX ou do centro do Rio de Janeiro no início do século XX. As periferias e favelas das cidades mantém condições de acúmulo de lixo, esgoto a céu aberto e superpovoamento. Os avanços sanitários do planejamento urbano durante o século XX não foram para todos.

\section{Reflexões a partir do cenário atual}

Historicamente a disciplina do urbanismo e o exercício de planejar o espaço urbano construído se desenvolveu como uma resposta a uma série de crises sanitárias e disseminação de doenças infecciosas do final do século XIX e início do século XX (Benevolo, 1993). Nesse momento, ao final da segunda década do século XXI, a disciplina se vê diante do desafio de resgatar suas origens e repensar sua atividade a partir da perspectiva de um mundo em constante estado de emergência sanitária. Segundo Burattini (2016) o mundo nas primeiras décadas do presente século sofreu com a expansão de surtos epidêmicos de doenças já conhecidas como a dengue e ebola, o surgimento de novas doenças como a Síndrome Respiratória Aguda Grave (SARS) e ainda o crescimento dos casos de doenças anteriormente consideradas raras e exóticas (como as causadas pelos vírus Chikungunya e Zika). Em setembro de 2019 a Organização Mundial de Saúde lança o documento A word at risk Annual report on global preparedness for health emergencies um primeiro relatório sobre os riscos e as necessidades de preparo, em escala global, frente a uma pandemia. Nesse relatório a OMS divulga dados referentes ao período entre 2011 e 2018 em que foram detectados 1483 eventos epidêmicos em 172 países.

“Doenças propensas a epidemias, como gripe, Síndrome Respiratória Aguda Grave (SARS), Síndrome Respiratória do Oriente Médio (MERS), Ebola, Zika, Febre Amarela e outros, são precursores de uma nova era de surtos de alto impacto e potencialmente de rápida disseminação, detectados com mais frequência e cada vez mais difíceis de gerenciar." (OMS, 2019, p. 12)

${ }^{1}$ Tradução dos autores.

ACE, 16 (46) CC BY-ND 3.0 ES | UPC Barcelona, España | Cidades em tempos de pandemia: um ensaio reflexivo.

DOI: http://dx.doi.org/10.5821/ace.16.46.9375 
A Figura 7 a seguir, presente no relatório da OMS, demonstra o surgimento de patógenos nos últimos 50 anos, ilustrando que o cenário da crise pandêmica causada pela disseminação do COVID19 nos ronda já a um tempo. A mesma OMS em 2018 afirma no artigo 10 amenazas a la salud mundial en 2018.

Figura 7. Histórico global de surgimento e ressurgimento de doenças

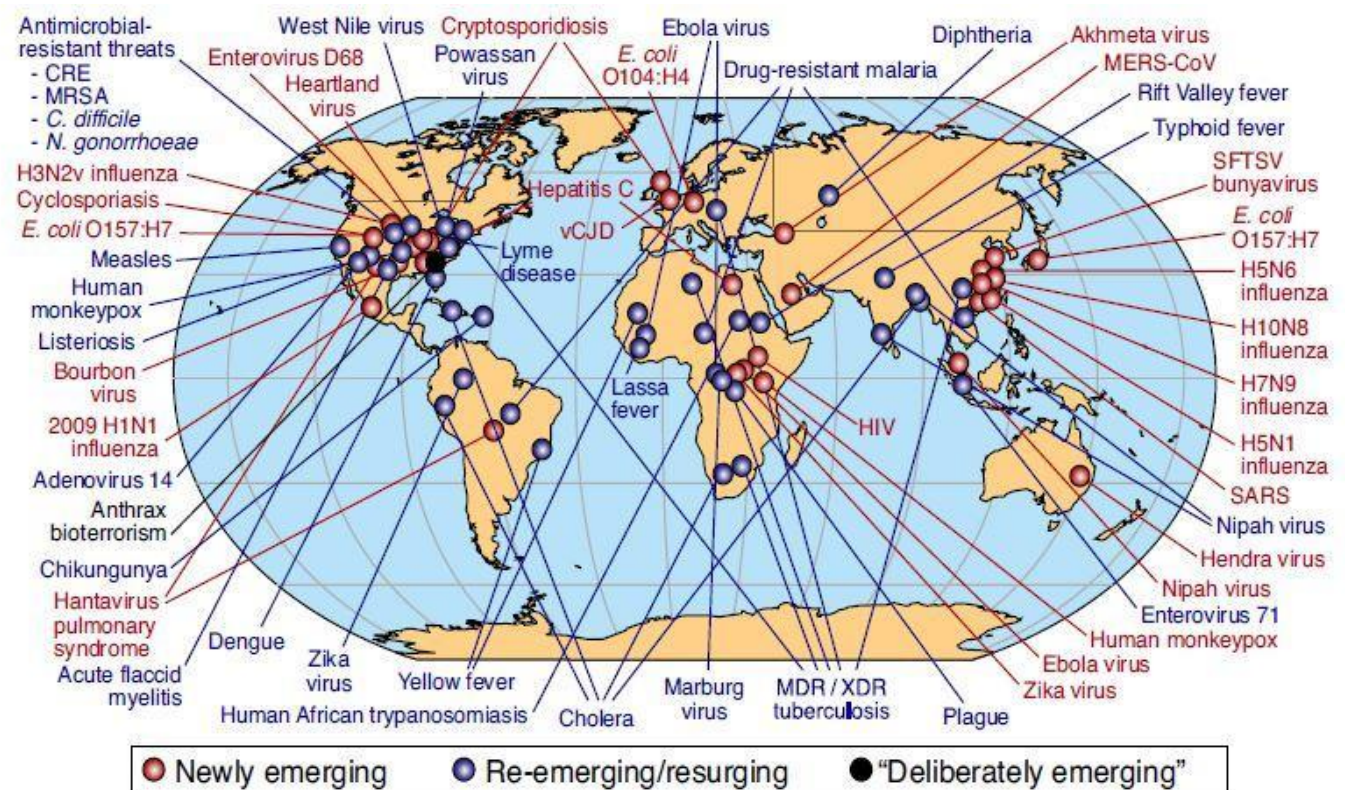

C. difficile: Clostridium difficile; CRE: carbapenem-resistant Enterobacteriaceae; E. coli: Escherichia coli; MDR: multidrugresistant [tuberculosis]; MERS-CoV: Middle East respiratory syndrome coronavirus; MRSA: meticillin-resistant Staphylococcus aureus; N. gonorrhoeae; Neisseria gonorrhoeae; SFTSV: severe fever with thrombocytopenia syndrome virus; XDR: extensively drug-resistant [tuberculosis].

Source: United States National Institutes of Health, National Institute for Allergies and Infectious Diseases (4).

Fonte: Organização Mundial de Saúde A word at risk - Annual report on global preparedness for health emergencies, 2019.

“É inevitável que se declare uma nova pandemia de gripe. Neste mundo interconectado, já se dão as condições para que se inicie o próximo surto mundial, que é só uma questão de tempo e terá consequências de amplo alcance.2" (OMS, 2018)

E no relatório de 2019 mantém sua reafirma os riscos existentes.

“(...) existe uma ameaça muito real de uma pandemia altamente letal em movimento rápido de um patógeno respiratório matando 50 a 80 milhões de pessoas e destruindo quase 5\% da economia mundial. Uma pandemia global nessa escala seria catastrófica, criando um caos generalizado, instabilidade e insegurança. O mundo não está preparado."” (OMS, 2019, p. 6)

A sociedade contemporânea, e consequentemente as cidades contemporâneas como espaço de materialização das relações sociais, criaram condições para que o COVID-19, e demais doenças infecciosas, se disseminasse pelo planeta. Em entrevista ao Conselho de Arquitetura e Urbanismo do Brasil (CAU-BR), publicada em 7 de maio de 2020, Paulo Saldiva, professor de patologia da Faculdade de Medicina da Universidade de São Paulo (USP), membro da Academia Nacional de Medicina e da

2 Tradução dos autores.

3 Tradução dos autores.

ACE, 16 (46) CC BY-ND 3.0 ES | UPC Barcelona, España | Cidades em tempos de pandemia: um ensaio reflexivo.

DOI: http://dx.doi.org/10.5821/ace.16.46.9375 
Academia Brasileira de Ciência e ex-presidente do Instituto de Estudos Avançados da USP, aponta as três principais causas da vulnerabilidade do mundo atual às infecções: o elevado adensamento, o intenso fluxo transcontinental de viajantes e o elevado uso de antibióticos multirresistentes por grande parte das pessoas. (Saldivia, 2020). Segundo análise de Saldiva (2020) será necessária a reorganização urbana a partir de uma nova lógica que impeça pontos de vulnerabilidade criados fundamentalmente por altíssimas taxas de crescimento e adensamento populacional.

"Todo vírus que tiver condições de se adaptar a esse novo cenário terá grandes chances de causar uma pandemia. Uma parte da letalidade do coronavírus é dependente dele mesmo e a outra parte nós que criamos as condições na nossa organização urbana e social”. (Saldiva, 2020)

A vulnerabilidade das pessoas ao coronavírus e a letalidade dele tem relação direta com as condições urbanas em que a população está inserida. Em uma mesma cidade as diferentes condições de acesso e distribuição de renda e serviços públicos resulta em diferentes taxas de mortalidade. A Secretaria de Saúde da cidade de São Paulo divulgou no dia 17 de abril o mapeamento (Figura 8) dos casos de óbitos por COVID, sobrepondo esses dados ao mapa de distribuição renda na cidade (Figura 9), tornase evidente a relação entre óbitos e desigualdades sociais. Por exemplo o bairro periférico Brasilândia registrou o maior número de mortes da cidade, 54 entre os 89 contaminados, enquanto o Morumbi, bairro de alta renda, registrou apenas 7 mortes apesar de ter um dos maiores índices de infectados, 297. "Essa enorme variação mostra que o código de endereçamento postal é tão importante quanto o código genético, pois na cidade a vulnerabilidade e a capacidade do indivíduo de fazer isolamento muda bastante" (Saldivia, 2020, p. 15).

Os dados mais recentes do Ministério da Saúde (29 de outubro de 2020) dão conta que o Brasil tem 158.468 mortes registrada por COVID-19, se consolidando o segundo país do mundo em número de morte e casos registrados, ficando atrás apenas dos Estados Unidos, somando até o momento 5.469.755 contaminados, são mais de 28 mil novos casos diários em todo o país. Por sua vez a cidade de São Paulo concentra quase 1/5 dos casos registrados e 25\% dos óbitos contabilizados, 1.156 .652 e 40.202 respectivamente, posicionando. (Ministério da Saúde, 2020). A partir dessa conjuntura arquitetos, urbanistas e planejadores urbanos brasileiros se reuniram no coletivo Urbanistas contra a corona (https://urbanismocontraocorona.blogspot.com), um manifesto online assinado por várias instituições, autoridades e especialistas da área que se propõe a pensar procedimentos de controle de pandemia em áreas urbanas, de ações imediatas além de propostas de médio e longo prazo.

Enquanto, essas iniciativas são pensadas a partir das relações sociais de um mundo pré-coronavírus, já durante a pandemia, é possível observar como as relações entre as pessoas e o espaço construído foi extremamente alterada. Seja o espaço das próprias casas que agora sobrepõe funções antes efetuadas no âmbito público, ou o espaço das cidades que se veem esvaziadas e com parte de seus equipamentos e serviços, até certo ponto, inutilizados.

Estamos diante de uma realidade em que, de acordo com os relatórios da OMS, crises sanitárias, epidemias e pandemias não serão apenas um risco, mas fenômenos recorrentes (OMS 2019), e as circunstâncias dadas para a recorrências desses fenômenos são características fundamentais do modelo de sociedade que vigora atualmente, grandes concentrações populacionais e intensa circulação transcontinental de pessoas. Dessa maneira, é seguro dizer que o futuro que nos aguarda será diferente do passado que abandonamos, antes da pandemia. A sociedade precisará adaptar-se, adaptar seus modelos de trabalho, relações sociais, deslocamento, lazer, e como efeito, a sua relação com o espaço construído. Casas e cidades terão seus valores e significados alterados a partir da nova realidade que se desenha. E como arquitetos urbanistas é nossa atribuição refletir criticamente sobre os futuros possíveis a partir de nossa disciplina.

ACE, 16 (46) CC BY-ND 3.0 ES | UPC Barcelona, España | Cidades em tempos de pandemia: um ensaio reflexivo. 10

DOI: http://dx.doi.org/10.5821/ace.16.46.9375 
Figura 8. Mortes suspeitas ou confirmadas de coronavírus na cidade de São Paulo até 17 de abril

\section{$(0,5)$ \\ CIDADE DE \\ SÃo PAULO}

\section{PREFEITURA DO MUNICÍPIO DE SÃO PAULO SECRETARIA MUNICIPAL DA SAÚDE}

igura 2 - Óbitos confirmados e suspeitos por Covid-19 segundo Distrito Administrativo (DA) c ısidência. Município de São Paulo,2020.

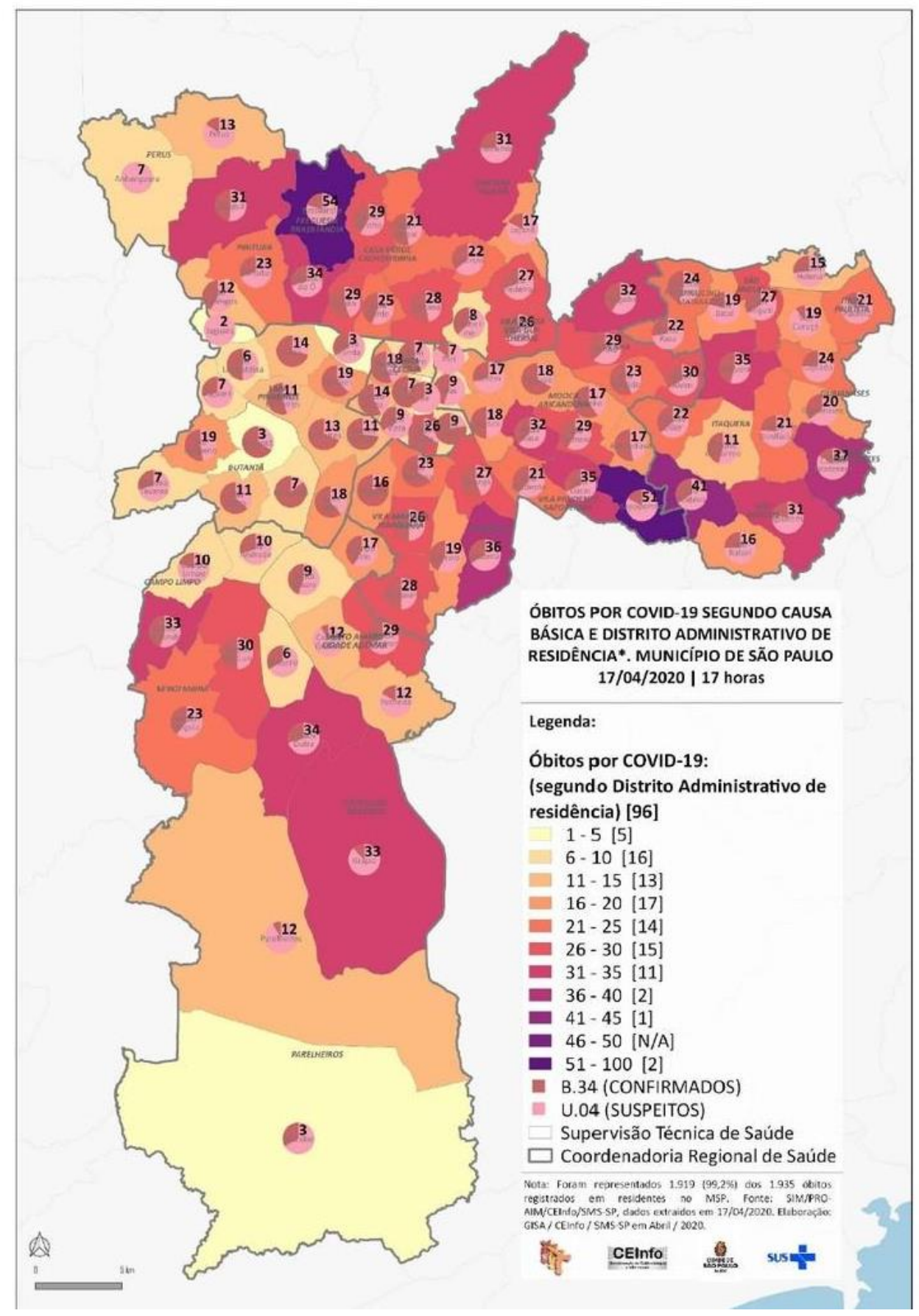

Fonte: Divulgação/Secretaria Municipal de Saúde

ACE, 16 (46) CC BY-ND 3.0 ES | UPC Barcelona, España | Cidades em tempos de pandemia: um ensaio reflexivo. 
Figura 9. Mapa da distribuição de renda no município de São Paulo no ano 2010
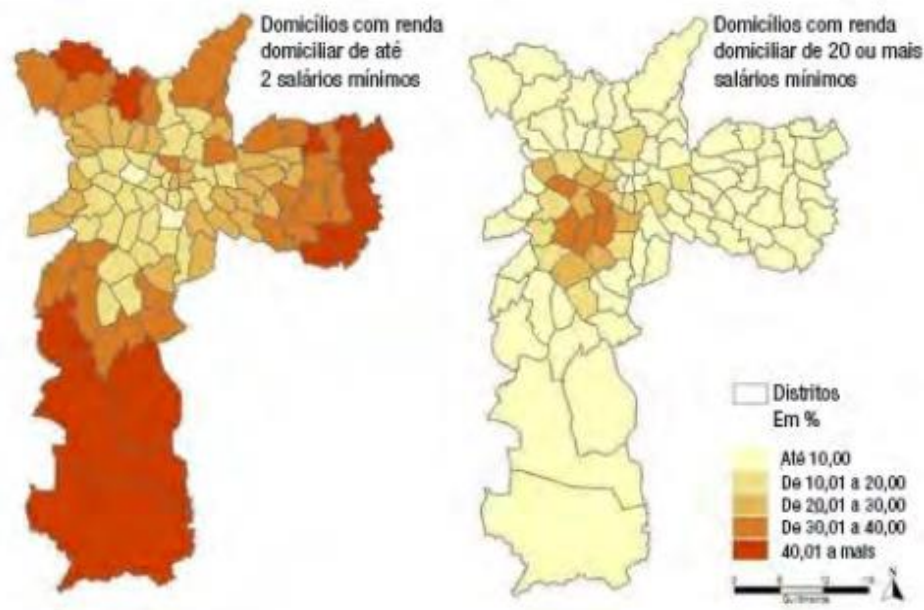

Fonte: Instituto Brasileiro de Geografia e Estatística (IBGE), 2015.

Figura 10. Aumento no número de downloads de aplicativos de videoconferências em março de 2020

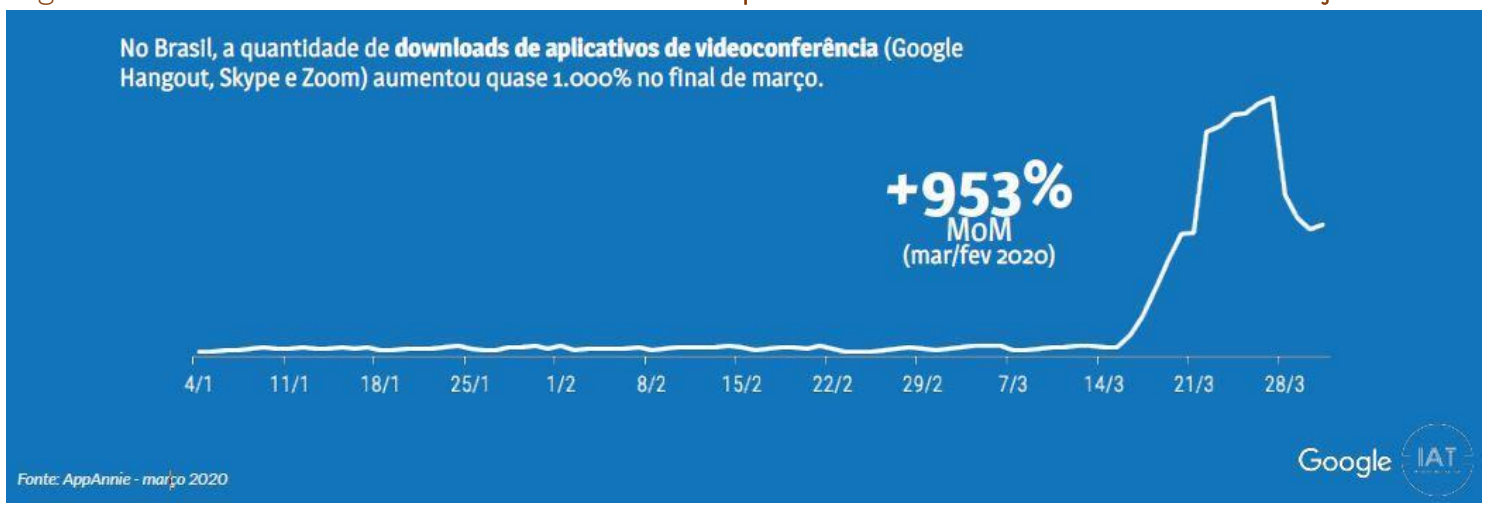

Fonte: Google e IAT, 2020

A primeira reflexão que se propõe é a partir das relações de trabalho. Segundo analistas do Google e da Integrate Analytic Teams (IAT), o COVID-19 acelerou a transição da sociedade para a banda larga e a digitalização em pelo menos uma década, durante o isolamento social, a internet torna-se o vetor principal para realização das atividades em todas as esferas (Google, IAT 2020). No Brasil foi registrado um aumento de 953\% de download de aplicativos de videoconferências (Figura 10).

As distâncias foram relativizadas por adventos da tecnologia da informação, dessa forma, o trabalho a distância se tornou para vários segmentos não só viável como vantajoso. Para o empregador existe a drástica diminuição de gastos com aluguel e contas básicas de infraestrutura, para o trabalhador a possibilidade de viver em cidades ou regiões com menor custo de vida e manterem seus trabalhos sem a preocupação do constante deslocamento. Em um cenário hipotético em que, em função dos benefícios financeiros e dos cuidados de isolamento social, uma parte significante de empresas e escritórios mantenha grande parte de suas equipes em trabalho a distância, reduzindo sua necessidade de espaço físico. O que será dos inúmeros edifícios empresariais e centros financeiros de cidades como São Paulo (figura 8) que podem ser desocupadas? Com o esvaziamento dessas áreas se observará uma alteração importante do seu valor econômico e simbólico. Regiões antes lidas como reflexos de poder e sucesso econômico se tornando abandonadas e obsoletas. Como reagiria o mercado imobiliário?

ACE, 16 (4.6) CC BY-ND 3.0 ES | UPC Barcelona, España | Cidades em tempos de pandemia: um ensaio reflexivo. 
Já é possível se ter alguns indícios das mudanças que a pandemia de COVID-19 estão causando nas cidades brasileiras, segundo reportagem "São Paulo, uma cidade para alugar" de 17 de agosto de 2020 do jornal El País (Svenson y Mendonça, 2020) y , a Fundação Instituto de Administração (FIA) aponta que até o momento $46 \%$ das empresas brasileiras adotaram a modalidade de trabalho remoto desde o início da crise sanitária, dentre essas empresas 34\% dessas empresas têm a intenção de manter pelo menos $1 / 4$ de suas equipes de maneira remota, enquanto $29 \%$ planeja manter entre metade a todos os seus funcionários em regime de home office. Enquanto a Associação dos Administradores de Bens Imóveis e Condomínios de São Paulo (AABIC) divulgou que o percentual de vacância de imóveis comerciais na cidade subiu de 20\% para 30\%. Esses bairros e regiões que concentram enormes investimentos públicos em infraestrutura poderiam ser reapropriadas pela especulação imobiliária ou apropriadas por uma nova lógica urbana que priorize a vida e o bem-estar das pessoas. Remodelados para habitação social, escolas e/ou faculdades públicas, unidades de atendimento do sistema público de saúde (Figura 11).

Figura 11. Avenida Paulista, São Paulo, Brasil, antes e durante a pandemia (2020)
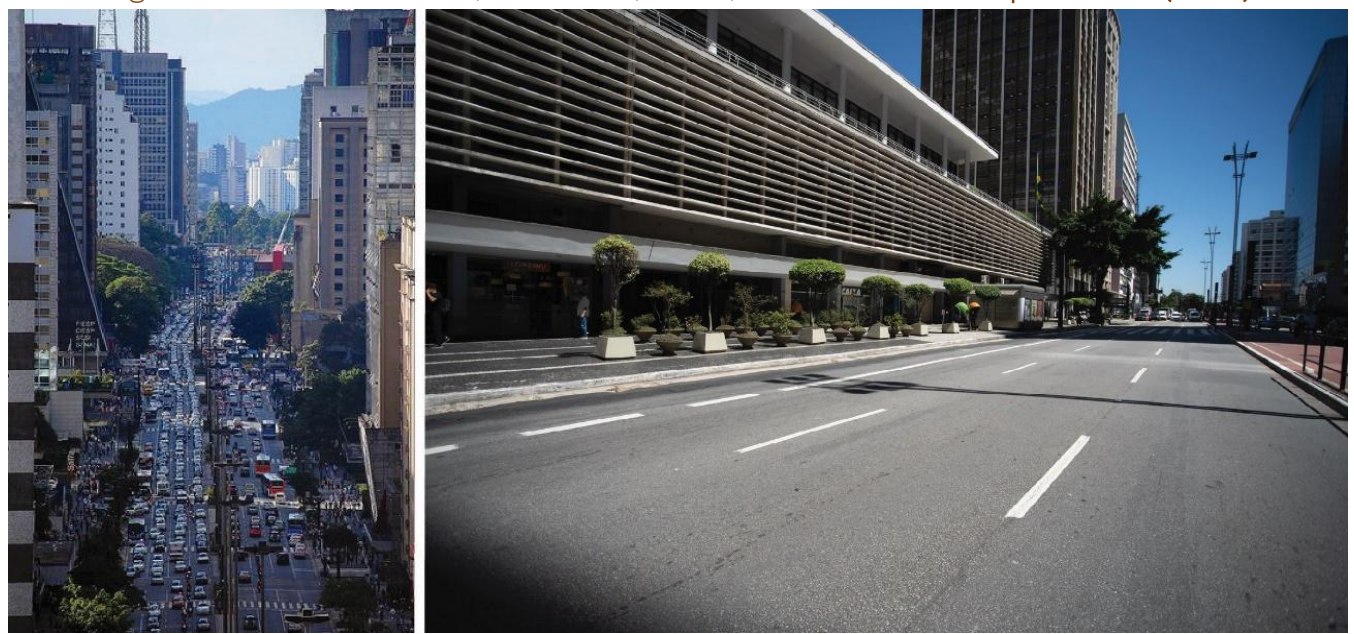

Fonte: https://g1.globo.com/bemestar/coronavirus/noticia/2020/03/24/coronavirus-cidades-vazias-pelo-mundofotos.ghtml

Em seguida, nos parece necessário refletir sobre o espaço a partir da lógica do consumo deles através do mercado turístico. No mundo pré-pandêmico, segundo relatório de 2018 da Associação Internacional de Transportes Aéreos (IATA), eram efetuados uma média de 107 mil voos por dia, embarcando cerca de 30 milhões de pessoas por mês, 50\% desses deslocamentos tiveram como motivação férias e lazer. Ainda segundo a mesma associação houve queda de $70 \%$ do tráfego aéreo mundial nos meses de isolamento (IATA 2020).

Assumindo o intenso fluxo transcontinental de pessoas como causa chave da disseminação, tão intensa e em tão curto período do COVID 19, o mundo, sob um novo modelo de controle de pandemias, seguramente vai tardar em recuperar essas cifras restringindo viagens com motivações turísticas. A lógica mercadológica que vende e consome cidades como atrações turísticas construiu no imaginário coletivo, com auxílio de produções culturais e midiáticas, o fetiche pela visitação de centenas de cidades pelo mundo. Cidades essas que, até então, recebiam milhares de visitantes por dia, verão esse fluxo diminuir drasticamente. Qual será o novo valor simbólico dessas cidades?

Imagina-se que a visitação restringida tornará esses espaços destinos ainda mais disputados e, ao contrário do que se considerou para as áreas financeiras e empresariais, os espaços de turismo se tornaram mais especulados e valorizados, e por consequência ainda mais elitizados. Os efeitos

ACE, 16 (46) CC BY-ND 3.0 ES | UPC Barcelona, España | Cidades em tempos de pandemia: um ensaio reflexivo. 13

DOI: http://dx.doi.org/10.5821/ace.16.46.9375 
possíveis seriam a acentuação dos processos de gentrificação, que substituiriam a população local por uma "composição cenográfica" de comércios e serviços voltados aos exclusivos visitantes de elite. O processo de democratização do acesso ao transporte aéreo que vimos acontecer nos últimos anos com a diminuição dos preços poderá ser revertido e as dinâmicas de deslocamento de médias e longas distâncias drasticamente alteradas.

\section{Pandemia e desigualdade social, uma relação recíproca}

Como demonstrado acima, as condições de salubridade das construções, as restrições de acesso a água e saneamento básico, moradias pequenas compartilhadas por muitas pessoas, sucateamento do sistema público de saúde, vulnerabilidade econômica e impossibilidade econômica de cumprir com o isolamento social são fatores que dificultam a proteção de mais de 1 bilhão de pessoas que segundo dado da ONU (2019) vivem em favelas e assentamentos informais. A situação de vulnerabilidade econômica e desigualdade social contribui para o aumento no número de contaminação e mortes pelo COVID 19. E, a recíproca é verdadeira. A crise pandêmica tende a agravar as desigualdades sociais. Estudos da Organização das Nações Unidas (ONU) preveem que os índices de pobreza mundial tendem a aumentar, pela primeira vez desde 1990, em razão da contingência sanitária, empurrando entre 420 e 580 milhões de pessoas a viver abaixo da linha da pobreza (ONU 2020; Sumner, et al., 2020).

A pandemia de COVID 19 evidenciou graves contradições na gestão urbana contemporânea. Há uma desigualdade enorme no acesso a equipamentos públicos, o desenho dos espaços públicos é insuficiente ou inadequado e a prioridade dada ao automóvel torna difícil a convivência entre a mobilidade dos pedestres, as áreas de descanso e as atividades econômicas. Além disso, o confinamento domiciliar traz outra questão que é a qualidade das habitações. A desigualdade na qualidade das residências é enorme mesmo nos países desenvolvidos. Inúmeras residências não alcançam os padrões básicos de qualidade e saúde ambiental. Casas minúsculas são compartilhadas com famílias numerosas e o problema da falta de habitação, ainda não resolvido, traz a questão: como pode ficar isolado em casa quem não possui uma casa? (Ezquiaga, 2020)

Para este momento há mais perguntas que respostas. Sem dúvida, é uma oportunidade para que o planejamento urbano e a arquitetura possam estudar formas de criar espaços e habitações saudáveis para toda a população. Os espaços urbanos evoluíram ao longo do século XX, criando áreas da cidade dotadas de saneamento, áreas arborizadas e habitações com iluminação e ventilação adequadas. Porém, esta não é a realidade para toda a população.

Como anunciava Mancuso (1980) os instrumentos urbanísticos não são ferramentas neutras, pelo contrário, servem para compor contradições e conflitos que surgem nas cidades, tendo sempre como objetivo conter e controlar os processos urbanos a partir dos interesses econômicos e políticosociais.

O resultado se vê no mundo todo, em periferias e favelas em que as condições de saneamento são extremamente precárias e as condições para o surgimento e a proliferação de epidemias são grandes. Mike Davis (2006) denuncia em seu livro Planet of slums que a favelização e a precarização do espaço e das condições de trabalho e vida nas cidades de países emergentes como o Brasil são uma realidade que afeta milhares de pessoas e que se perpetua devido a planos de ajuste econômico e de austeridade. Como a cidade é um reflexo da própria sociedade, resta a pergunta: o século XXI ainda vai negligenciar a desigualdade? O que pode mudar em nossas cidades devido às pandemias deste início de século?

ACE, 16 (46) CC BY-ND 3.0 ES | UPC Barcelona, España | Cidades em tempos de pandemia: um ensaio reflexivo. 14

DOI: http://dx.doi.org/10.5821/ace.16.46.9375 
Segundo Raquel Rolnik (2020) a crise sanitária global apenas escancarou a crise em um modelo de desenvolvimento baseado na expansão ilimitada e inconsequente, que se resulta insustentável social e ecologicamente. Nesse momento está dada aos arquitetos urbanistas a oportunidade de pensar o novo modelo de cidade, seguiremos construindo a partir do urbanismo hegemônico estabelecido pela e para a "renda", ou disputaremos recursos públicos e o protagonismo de um planejamento de cidade pela e para a vida? (Rolnik, 2020).

\section{Autoria}

O autor 2 desenvolveu a discussão histórica em que relaciona as emergências sanitárias aos avanços do urbanismo como disciplina ao longo dos últimos dois séculos. A autora 1 desenvolveu as análises e discussões críticas referentes a pandemia de COVID-19 em que reflete as influências desse cenário nas cidades contemporâneas.

Conflito de interesses: Os autores declaram não haver conflito de interesses.

\section{Bibliografia}

Andrade, Carlos Roberto Monteiro de. De Viena a Santos: Camillo Sitte e Saturnino de Brito. In: SITTE, Camillo. A construção das cidades segundo seus princípios artísticos. São Paulo: Ática, 1992.

Benevolo, Leonardo. (1993) História da Cidade. São Paulo, Brasil: Editora Perspectiva.

Burattini, Marcelo Nascimento. (2016). Doenças infecciosas no Século XXI. Acta Paulista de Enfermagem, 29(2), III-VI. https://doi.org/10.1590/1982-0194201600018

Cerdá, I. (1867). Teoría general de la urbanización y aplicación de sus principios y doctrinas a la reforma y ensanche de Barcelona. Madrid, España: Imprenta Española. Dos volúmenes. Reimpresión facsímil en Estapé (1968).

Chalhoub, S. (2006) Cidade Febril: Cortiços e Epidemias na Corte Imperial. São Paulo, Brasil: Companhia das Letras.

Davis, M. (2006). Planet of Slums, Londres, Inglaterra: Verso.

Ezquiaga, J. (2020). Hay que Defender la Ciudad: De la Distopía del Confinamiento a la Ciudad Abierta. ACE Architecture, City and Environment, 15(43), 9518. DOI: http://dx.doi.org/10.5821/ace.15.43.9518

Fundação Fiocruz (s/d). Reforma Pereira Passos. Recuperado de: http://oswaldocruz.fiocruz.br/index.php/biografia/trajetoria-cientifica/na-diretoria-geral-de-saudepublica/reforma-pereira-passos

Glancey, Jonathan. (2016) O homem que construiu a Paris que conhecemos hoje. Recuperado de: https://www.bbc.com/portuguese/noticias/2016/02/160203_vert_cul_criador_paris_lab

Gonçalves, A., Sant'anna, A., Carstens, F., \& Fleith, R. (1991) O que é urbanismo. São Paulo, Brasil: Brasiliense. Google, Integrate Analytic Teams (IAT) (2020). Coronavírus: O mundo nunca mais será o mesmo. São Paulo, Brasil.

International Air Transport Association. (2019) Annual Review from 2018. Recuperado de: https://www.iata.org/contentassets/c81222d96c9a4e0bb4ff6ced0126fobb/iata-annual-review-2018.pdf

ACE, 16 (4.6) CC BY-ND 3.0 ES | UPC Barcelona, España | Cidades em tempos de pandemia: um ensaio reflexivo.

DOI: http://dx.doi.org/10.5821/ace.16.46.9375 
International Air Transport Association. (2020). COVID-19 Outlook for air travel in the next 5 years. Recuperado de: https://www.iata.org/en/iata-repository/publications/economic-reports/covid-19-outlookfor-air-travel-in-the-next-5-years/

Macedo, Jose Emerson Tavares de. A cidade de Londres no século XIX: uma abordagem sobre os marginalizados. (2008) Revista Alpharrabios. Universidade Estadual da Paraíba. 2 (1).

Mancuso, F. (1980) Las experiencias del zoning. Barcelona: Editora Gustavo Gili, 380p.

Ministério de Saúde do Brasil (2020). Painél Coronavírus. Recuperado de: https://covid.saude.gov.br/

Müller, G. (2002) A Influência do Urbanismo Sanitarista na Transformação do Espaço Urbano em Florianópolis. [Dissertação (mestrado)]. Universidade Federal de Santa Catarina, Centro de Filosofia e Ciências Humanas. Programa de Pós-Graduação em Geografia. Disponível em: https://repositorio.ufsc.br/xmlui/handle/123456789/83510

Oliveira Sobrinho, A. (2013). São Paulo e a Ideologia Higienista entre os séculos XIX e XX: a utopia da civilidade. Revista Sociologias 15 (32) 210-235. https://www.scielo.br/pdf/soc/v15n32/09.pdf

Organização Mundial de Saúde (2018). 10 amenazas a la salud mundial en 2018. Recuperado de: https://www.who.int/features/2018/10-threats-global-heath/es/

Organização Mundial de Saúde. (2019) A World at Risk. Annual report on global preparedness for health emergencies. $\quad$ Recuperado https://apps.who.int/gpmb/assets/annual report/GPMB annualreport 2019.pdf.

Organização das Nações Unidas. (2019) Sustainable Developments Goals. Recuperado de: https://unstats.un.org/sdgs/report/2019/goal-11/

Rolnik, R. \& Wisnik, G. (2020) Utopias e distopias urbanas em tempo de pandemia. [Arquivo de vídeo]. Recuperado de: https://www.youtube.com/watch?v=31sXhys8ge8

Saldiva, P. (2020). Patologista aponta a necessidade de replanejamento das cidades. O modelo das cidades brasileiras e algumas implicações com o coronavírus. Recuperado de: https://www.caubr.gov.br/patologista-aponta-a-necessidade-de-replanejamento-das-cidades/

Secretaria Municipal de Saúde da cidade de São Paulo. (2020). COVID-19 Boletim Semanal de 17 de abril de $2020 . \quad$ Recuperado de: https://www.prefeitura.sp.gov.br/cidade/secretarias/upload/saude/PMSP_SMS_COVID19_Boletim\%20Sema nal_20200417_atualizado.pdf.

Sumner, A., Hoy, C., \& Ortiz-Juarez, E. (2020). Estimates of the impact of COVID-19 on global poverty. WIDER Working Paper, 43. https://doi.org/10.35188/UNU-WIDER/2020/800-9

Svenson, C., \& Mendonça, H. (2020) São Paulo, uma cidade para alugar. El País. Disponível em https://brasil.elpais.com/brasil/2020/08/01/album/1596233902 742829.html

Villaça, Flávio. (1997). A Delimitação Territorial do Processo Urbano. São Paulo, Brasil. Recuperado de: http://flaviovillaça.arq.br/pdf/infra497.pdf

Villaça, Flávio. (2012) Reflexões sobre as cidades brasileiras. São Paulo, Brasil: Studio Nobel.

ACE, 16 (46) CC BY-ND 3.0 ES | UPC Barcelona, España | Cidades em tempos de pandemia: um ensaio reflexivo.

DOI: http://dx.doi.org/10.5821/ace.16.46.9375 